\title{
Allelopathic Effects of Leaf Extracts of Glycosmis pentaphylla (Retz.) DC. on Triticum aestivum (L.) and Vigna radiata (L.) Wilczek
}

\author{
Vinitha S Babu, ${ }^{1, *}$, Anice Kurian $\mathbf{M}^{2}$, PM Radhamany ${ }^{3}$ \\ ${ }^{1}$ Plant Reproductive Biology Laboratory, Department of Botany, University of Kerala, Kariavattom, \\ Thiruvananthapuram, Kerala, India \\ ${ }^{2}$ Department of Botany, Deva Matha College, Kuravilagad, Kerala, India \\ ${ }^{3}$ Department of Botany, University of Kerala, Kariavattom, Thiruvananthapuram, Kerala, India
}

Received April 23, 2020; Revised May 11, 2020; Accepted June 23, 2020

Copyright $\mathrm{C} 2020$ by authors, all rights reserved. Authors agree that this article remains permanently open access under the terms of the Creative Commons Attribution License 4.0 International License

\begin{abstract}
Medicinal and aromatic plants have the ability to transmit volatile allelochemicals and affect their surrounding organisms. In this regard, their interaction should also be considered. Allelopathy can be widely used in agricultural practices considering their profound role in seed germination. The study presented in this work was designed to evaluate the allelopathic effects of Glycosmis pentaphylla (Retz.) DC. on the growth of a monocot plant Triticum aestivum (L.) and a dicot plant Vigna radiata (L.) Wilczek. This is the first report of a study on allelopathy in Glycosmis pentaphylla. Aqueous leaf extracts were used for the study. Parameters like germination percentage, plumule length, radical length, vigour index and percentage phytotoxicity of the seedlings were determined in a paper test. Concentration of the extract ranging from 2-10 $\mathrm{ml}$ along with a control was made to germinate the seedlings. The results were statistically tested by one-way ANOVA. The results revealed that, except for percentage phytotoxicity, all the parameters were indirectly proportional to the concentration of the extract applied. On the other hand, the percentage phytotoxicity was directly proportional to the concentration of the extract. The germination percentage (101.0 \pm 0.70$)$, plumule length $(8.51 \pm 0.005)$, vigour index $(851.2 \pm 0.58)$ and percentage phytotoxicity $(65.52 \pm 0.005)$ were found maximum for Vigna radiata than Triticum aestivum. On the other hand, $T$. aestivum showed the highest value for radicle length which was $3.20 \pm 0.06$. Hence, it can be gleaned from the results that, the dicot plant showed maximum growth due to the allelochemicals obtained from G. pentaphylla. As the study plants belong to the family Rutaceae, which is highly rich in aromatic oils, this might be a probable reason for the growth of test plants. The present study also indicates that, the allelochemicals released from G. pentaphylla were also
\end{abstract}

responsible for the induction of variation in the germination of seedlings.

Keywords Glycosmis pentaphylla, Allelopathy, Triticum aestivum, Vigna radiata, Growth Parameters

\section{Introduction}

Allelopathy is defined as process where a plant secretes allelochemicals which can directly or indirectly affect the growth of the nearby plants. Often, confusions have arisen in the literature because some biologists consider allelopathy to be a detrimental phenomenon whereas some others consider it as beneficial. This confusion could be lessened by using the term 'allelopathy' to refer to the overall influence of one plant on another [1]. Medicinal plants have invariably been a rich source of modern drug discoveries. Many drugs in use today were either obtained from plants or developed using their chemical structure as templates. They play an important role in health care dynamics throughout the world for health security. Improvement of allelopathic properties of crop cultivars can be achieved by traditional breeding or by genetic manipulation. So far, no crop with strong allelopathic activity has apparently been developed, but research in this area is receiving attention. At least for barley and wheat, some of the genes involved in the production of allelochemicals have been located. Apart from genotype, the production and/or release of allelochemicals from crops, e.g. rye, wheat, barley and rice, typically depend on the developmental stage of the plant and/or on external factors such as temperature, nutrient status and herbivory. In the 
present work, a comparison has been made using allelochemicals secreted by leaf of Glycosmis pentaphylla between a monocot plant Triticum aestivum (wheat) and a dicot plant Vigna radiata (mung bean). Glycosmis pentaphylla, known as a tooth brush tree is a member of the citrus family Rutaceae and is commonly known as orange berry and gin berry. The word Glycosmis is derived from Greek where "Glykys" means sweet and "Osme" means smell; alluding to the sweet scented flowers. The family Rutaceae contains about 100 genera and 800 species of herbs and G. pentaphylla is a shrub or a small trees [2]. It is distributed in Bangladesh, India, Malaysia, Southern China to Philippines, and Australia [3]. Being a member of the Rutaceae family, the plant is endowed with gland-dots rich in essential and aromatic oil. Some of the major classes of compounds reported from $G$. pentaphylla include terpenoids, amides, imides, alkaloids, coumarin, and flavonoids [4]. Several authors investigated the plant for anti-inflammatory efficacy [5], hepatoprotective activity [6] antimicrobial effect [7], and antipyretic potential [8]. The test crops used for the study were $T$. aestivum and $V$. radiata. These plants were selected as they possessed rapid germination and growth within a limited period of time. Both these test crops are richest source of nutrition as they contain essential elements for growth and survival of human beings. Significant work has been done on the phytochemical composition of G. pentaphylla, but there are no reports regarding the allelopathic potential of this plant till date. In the present study, parameters like germination percentage, length of radical, length of plumule, percentage phytotoxicity are determined. Another important parameter, the vigour index has also been determined. Seed vigour is defined as "the sum total of those properties of the seed which determine the level of activity and performance of the seed of seed lot during germination and seedling emergence. Seeds which perform well are termed 'high vigour' seeds [9]. Thus, the present study deals with alleopathic potential of G. pentaphylla on wheat and mung bean.

\section{Materials and Methods}

\subsection{Plant Materials}

For the experiment fresh leaves of Glycosmis pentaphylla were collected from the district of Thodupuzha (Latitude- $9.8959^{\circ} \mathrm{N}$ and Longitude- $76.7184^{\circ} \mathrm{S}$ ), Kerala, India. The leaves were thoroughly washed under running tap water, rinsed with distilled water and dried under shade for two weeks. The dried leaves were then powdered using an electric blender and passed through a mesh sieve to remove the visible plant residues. These were then stored in airtight bottles to free from moisture and humidity until further experimental usage. The aqueous extract of leaves were prepared by soaking $5 \mathrm{~g}$ of powder in $100 \mathrm{ml}$ distilled water for 24 hours, at room temperature for the preparation of $2 \%, 4 \%, 6 \%, 8 \%$ and $10 \%$ concentrations. The solution was firstly passed through the cotton cloth and then further filtered through Whatman No.1 filter paper. Fresh, healthy and disease free seeds of Triticum aestivum and Vigna radiata were purchased from a local market and were soaked in 5\% sodium hypochlorite for 10 minutes and then they were washed with distilled water. Seeds soaked in distilled water used as control treatment. For germination test, 20 seeds were placed in $12 \mathrm{~cm}$ petri dishes on two layers of filter paper and $5 \mathrm{ml}$ of distilled water for control and $5 \mathrm{ml}$ from levels of expected extract were added to it. The lids of containers with the temperature $25^{\circ} \mathrm{C}$ were prepared ( 12 hours in the day and 12 hours in the night). It took 5 days for Triticum aestivum seeds to germinate and 3 days for the germination of Vigna radiata seeds. Every day, the germinated seeds were numbered in the certain time. The criterion of radical exit germination has been considered $1 \mathrm{~mm}$. At the end of germination test, the length of radical and coleoptiles were measured. Both radical length (root) and plumule (shoot) length were measured using a ruler in $\mathrm{cm}$. Also, at the end, the extreme percent of germination and the rate of germination were accounted. Along with that, vigour index and percentage phytotoxicity were also calculated.

\subsection{Parameters Evaluated}

Observations on seed germination and other growth parameters were recorded in the following manner based on standard protocols [10]:

\subsubsection{Seed Germination (\%)}

After the completion of germination in all replication, the germination per cent was calculated for each treatment.

$$
\text { Germination } \%=\frac{\text { No.of seeds germinated }}{\text { Total no.of seeds }} \times 100
$$

Protrusion of radical as well as emergence of cotyledons through the seed coat was taken as the criterion for germination. Percentage of germination was expressed on the basis of the total number of seeds tried for germination.

\subsubsection{Length of Radicle $(\mathrm{cm})$}

The root length was measured with the help of a ruler from collar region to the tip of the longest root, after removing the seedling from the petri plates/ polythene bags. It was the average length of five roots recorded per seedling.

\subsubsection{Length of Plumule $(\mathrm{cm})$}

The plumule length was measured with the help of a ruler, and the average length of five roots recorded per seedling.

\subsubsection{Vigour Index}

Vigour index was calculated using the formula 
Vigour index $=$ Germination percentage $\times$ Length of the Axis

\subsubsection{Percentage of Phytotoxicity}

The percent phytotoxicity was calculated [11] using the formula:

Radicle length of Control - Radicle length of Test
$\times 100 \quad$ Radicle length of Control

\subsection{Statistical Analysis}

Analysis of variance (ANOVA) was used to determine the significant differences. The Multiple Range Test of Duncan performed the separation means (P) using SPSS software (version 22.0).

\section{Results and Discussion}

Plants have traditionally been used as a source of medicine in India by indigenous people of different ethnic groups inhabiting in various terrains for the control of various ailments afflicting human and their domestic animals [12]. The medicinal values of the plants are due to the bioactive constituents that produce definite physiological action on the human body [13]. But, the allelopathic potential of most of the medicinal plants are unknown. In these circumstances, there is lack of knowledge or information on the allelopathic effect of Glycosmis pentaphylla on the growth and development of the plants. Several researchers have reported the release of a variety of secondary metabolites by Jatropha through leaching, root exudation etc.[14]. These secondary metabolites may influence the growth and development of the nearby plants by eliciting stimulatory or inhibitory responses [15]. In this context, an important medicinal plant $G$. pentaphylla was used to check its allelopathic potential on a monocot plant wheat and a dicot plant mung bean. The results of the present study indicates that the aqueous leaf extract of G. pentaphylla has profound effect on the growth and germination of Triticum aestivum and Vigna radiata. The study revealed that, the germination percentage was inversely proportional to the concentration of aqueous leaf extract used. As the concentration of extract increased, the seed germination percentage decreased. It was also seen that, the seed germination percentage was higher for Vigna radiata seeds than the monocot plant Triticum aestivum. A similar study was made [16, 17] on the effect of aqueous extracts of Jatropha curcas on four traditional crops (Phaseolus vulgaris, Zea mays, Lycopersicon lycopersicum \& Hibiscus esculentus). Aqueous extracts from leaves (L) and roots (R) of Jatropha curcas were prepared at different concentrations of $2 \%, 4 \%$, $6 \%, 8 \%, 10 \%$ and applied to the test crops. The study reported that all the crops were affected by different concentrations of aqueous extracts. Several researchers have reported the allelopathic effect of many plant extracts on the growth of shoot viz., Asphodelus tenuifolius and Fumaria indica in growth of maize $[18,19,20]$, by Leucaena leucocephala on mungbean and soybean [21], by Prosopis juliflera on wheat [22]. In G. pentaphylla, the bioassay result revealed that the inhibitory effect on shoot growth was observed in wheat and mung bean. The effect was highly significant in Vigna radiata seeds than the monocot plant Triticum aestivum. The extract of $G$. pentaphylla leaf showed the inhibitory effect on root growth of wheat and mung bean in all treatment as compared with the control plants. In both the crop plants, the drastic reduction in the root growth was observed at the highest concentration. The root length was higher in wheat than in mung bean. The inhibition to root length may be due to the size of the seeds. As sensitivity of plants to allelochemicals is related to seed size [23], the larger seed size of the crop plants was less affected than smaller seed size. In the present study seed vigour was also determined. Seed vigour comprises those seed properties which determine the potential for rapid uniform emergence, and development of normal seedlings under a wide range of field conditions. It was seen that, the vigour index was higher for Vigna radiata seeds than the monocot plant Triticum aestivum. Hence, it can be said that, the leaf extract of Glycosmis pentaphylla showed profound activity in the germination of $V$. radiata seeds than $T$. aestivum. Also, the vigour index was inversely proportional to the concentration of extract used. In the present study, phytotoxicity was also measured. Phytotoxicity is defined as a delay of seed germination, inhibition of plant growth or any adverse effect on plants caused by specific substances (phytotoxins) or growing conditions. In chemical research, it is possible to determine a number of important parameters and also to indicate certain dangers with respect to plant growth. However, it is practically impossible to screen a material for all substances which might cause damage. In order to assess whether there are harmful substances present in a material, a plant response test may be helpful. Such a test does not give definitive answers as not all crops react the same and the reason for a possible effect can only be assumed, but it does give more confidence about the suitability of a growing medium or a growing medium constituent. The results of phytotoxicity study revealed that, it was directly proportional to the concentration of aqueous leaf extract used. As the concentration of extract increased, the phytotoxicity increased. It was also seen that the percentage phytotoxicity was higher for $V$. radiata seeds than the monocot plant $T$. aestivum. This might be because of the increased radical length of $T$. aestivum than $V$. radiata. As both phytotoxicity and vigour index is calculated based on radical length as one of the parameter, a negative correlation can be obtained between the parameters evaluated. All the results are summarized in Table 1. 
Table 1. Results of parameters evaluated for the study

\begin{tabular}{|c|c|c|c|c|c|c|}
\hline $\begin{array}{c}\text { Seeds } \\
\text { selected for } \\
\text { the study }\end{array}$ & Concentration & $\begin{array}{c}\text { Seed } \\
\text { germination }\end{array}$ & $\begin{array}{c}\text { Length of } \\
\text { Radicle (cm) }\end{array}$ & $\begin{array}{c}\text { Length of } \\
\text { plumule (cm) }\end{array}$ & Vigour Index & $\begin{array}{c}\text { Percentage } \\
\text { phytotoxicity }\end{array}$ \\
\hline \multirow{7}{*}{$\begin{array}{l}\text { Triticum } \\
\text { aestivum }\end{array}$} & Control & $98.8 \pm 0.58$ & $3.41 \pm 0.010$ & $5.91 \pm 0.007$ & $590.0 \pm 0.70$ & \\
\hline & $2 \mathrm{ml}$ & $80.0 \pm 0.70$ & $3.20 \pm 0.006$ & $4.80 \pm 0.003$ & $384.6 \pm 0.50$ & $5.87 \pm 0.007$ \\
\hline & $4 \mathrm{ml}$ & $70.4 \pm 0.50$ & $3.02 \pm 0.008$ & $3.91 \pm 0.007$ & $272.8 \pm 0.58$ & $11.75 \pm 0.005$ \\
\hline & $6 \mathrm{ml}$ & $70.0 \pm 0.83$ & $2.5 \pm 0.007$ & $3.21 \pm 0.005$ & $224.6 \pm 0.50$ & $26.46 \pm 0.009$ \\
\hline & $8 \mathrm{ml}$ & $60.0 \pm 0.70$ & $2.1 \pm 0.005$ & $2.91 \pm 0.005$ & $174.6 \pm 0.50$ & $38.21 \pm 0.005$ \\
\hline & $10 \mathrm{ml}$ & $50.0 \pm 0.70$ & $1.6 \pm 0.005$ & $1.72 \pm 0.007$ & $86.0 \pm 0.70$ & $51.46 \pm 0.007$ \\
\hline & $\begin{array}{c}\text { Treatment } \\
\mathrm{df}(\mathrm{n}-1)\end{array}$ & $1415.493^{* * *}$ & $8528.196^{* * *}$ & $5627.172 * * *$ & $8968.652 * * *$ & $6959.985^{* * *}$ \\
\hline \multirow{7}{*}{$\begin{array}{l}\text { Vigna } \\
\text { radiata }\end{array}$} & Control & $99.0 \pm 0.70$ & $2.91 \pm 0.008$ & $9.41 \pm 0.005$ & $941.2 \pm 0.58$ & \\
\hline & $2 \mathrm{ml}$ & $101.0 \pm 0.70$ & $2.67 \pm 0.046$ & $8.51 \pm 0.005$ & $851.2 \pm 0.58$ & $10.34 \pm 0.005$ \\
\hline & $4 \mathrm{ml}$ & $98.8 \pm 1.06$ & $2.02 \pm 0.007$ & $7.31 \pm 0.005$ & $731.2 \pm 0.58$ & $31.03 \pm 0.005$ \\
\hline & $6 \mathrm{ml}$ & $90.0 \pm 0.70$ & $1.62 \pm 0.008$ & $4.61 \pm 0.001$ & $621.6 \pm 0.50$ & $44.83 \pm 0.007$ \\
\hline & $8 \mathrm{ml}$ & $89.2 \pm 0.86$ & $1.52 \pm 0.007$ & $5.50 \pm 0.005$ & $496.2 \pm 0.58$ & $48.26 \pm 0.007$ \\
\hline & $10 \mathrm{ml}$ & $70.0 \pm 0.70$ & $1.02 \pm 0.008$ & $4.91 \pm 0.007$ & $343.4 \pm 0.92$ & $65.52 \pm 0.005$ \\
\hline & $\begin{array}{l}\text { Treatment } \\
\mathrm{df}(\mathrm{n}-1)\end{array}$ & $669.413^{* * *}$ & $1246.261^{* * *}$ & $5827.629 * * *$ & $12055.082 * * *$ & $1108.647 * * *$ \\
\hline
\end{tabular}

The representative experiment is a mean standard error followed by different superscript lowercase letters indicate significant difference between each parameter as evaluated by Duncan's Multiple Range Test. f value significant at $* \mathrm{P} \leq 0.001$ level, NS- non significant.

\section{Conclusions}

The present investigation reveals that the allelochemicals released from Glycosmis pentaphylla are responsible for the induction of variation in the seedling as well as germination of both wheat and mung bean. Even though the effects obtained under laboratory conditions are not necessarily significant in the field, it can be concluded that, there are compunds in $G$. pentaphylla which may cause allelopathic effects also under field conditions, if the compounds are released in some way. In the present context, control treatment had obtained the highest growth. Except for percentage phytotoxicity, all experimental characteristics decreased with increase in G. pentaphylla extract densities. Vigna radiata possessed maximum values for all the parameters than Triticum aestivum except for radical length. Hence, this might be the reason for an increased phytotoxicity percentage in $V$. radiata as phytotoxicity is measured on the basis of radical length. Moreover, the allelochemicals which are responsible for germination and growth reduction of different crops, should be identified in future studies.

\section{Acknowledgements}

Authors are thankful to Principal, Deva Matha College, Kuravilangad for providing laboratory facilities to carry out this study.

\section{REFERENCES}

[1] C. H Muller. Allelopathy as a factor in ecological process. Vegetatio, Vol. 7, No. 1, 348-357, 1969.

[2] C. P. Khare. Indian medicinal plants: an illustrated dictionary. New York, U.S.A: Springer Science, 2008.

[3] Z. L. Zhao, G. Dorje, Z. T. Wang, Z. T. Identification of medicinal plants used as Tibetan traditional medicine Jie-Ji. Journal of ethnopharmacology, Vol. 132, No. 1, 122-126, 2010.

[4] M. Panghal, V. Arya, S. Yadav, S. Kumar, J. P Yadav. Indigenous knowledge of medicinal plants used by Saperas community of Khetawas, Jhajjar District, Haryana, India. Journal of Ethnobiology and Ethnomedicine, Vol. 6, No. 1, 2010 .

[5] A. C. Akinmoladun, E. O. Ibukun, E. Afor, E. M. Obuotor. Phytochemical constituent and antioxidant activity of extract from the leaves of Ocimum gratissimum. Sci Res Essay, Vol. 2, No. 5, 163-166, 2007.

[6] A. Nwokocha, I.O Blessing, Agbagwa, \& B. E. Okoli. Comparative phytochemical screening of Jatropha L. species in the Niger Delta. Research Journal of Phytochemistry, Vol. 5, No. 2, 107-114, 2011.

[7] G. R. Waller. Biochemical frontiers of allelopathy. Biologia Plantarum, Vol. 31, No. 6, 418, 1989. 
[8] S. Abugre, J. Q. Sam. Evaluating the allelopathic effect of Jatropha curcas aqueous extract on germination, radicle and plumule length of crops. Int J Agric Biol, Vol. 12, No. 1, 769-772, 2010.

[9] M. Rob, K. Hossen, A. Iwasaki, K. Suenaga, H. Kato-Noguchi. Phytotoxic Activity and Identification of Phytotoxic Substances from Schumannianthus dichotomus. Plants, Vol. 9, No. 1, 102, 2020.

[10] W. Wang, P. H. Keturi. Comparative seed germination tests using ten plant species for toxicity assessment of a metal engraving effluent sample. Water, Air, and Soil Pollution, Vol. 52, No.3, 369-376, 1990.

[11] J. K Datta, A. Bandhyopadhyay, A. Banerjee, N. K. Mondal. Phytotoxic effect of chromium on the germination, seedling growth of some wheat (Triticum aestivum L.) cultivars under laboratory condition. Journal of Agricultural Technology, Vol. 7, No. 2, 395-402, 2011.

[12] N. Jabeen, M. Ahmed. Possible allelopathic effects of three different weeds on germination and growth of maize (Zea mays) cultivars. Pak. J. Bot, Vol. 41, No. 4, 1677-1683, 2009.

[13] T. L. Shapla, R. Parvin, M. H. A Amin, S. M Rayhan. Allelopathic effects of multipurpose tree species Melia azedarach with emphasis on agricultural crops. Journal of Innovation and Development Strategy, Vol. 5, No. 1, 70-77, 2011.

[14] S. Siddiqui, S. Bhardwaj, S. S. Khan, M. K. Meghvanshi. Allelopathic effect of different concentration of water extract of Prosopsis juliflora leaf on seed germination and radicle length of wheat (Triticum aestivum Var-Lok-1). American-Eurasian Journal of Scientific Research, Vol. 4, No. 2, 81-84, 2009.

[15] R. M. Heisey, R. M. Allelopathic and herbicidal effects of extracts from tree of heaven (Ailanthus altissima). American Journal of Botany, Vol. 77, No. 5, 662-670, 1990.
[16] D. A. Perry. Report of the vigour test committee 1974-1977. U. S. A: Seed Science and Technology, 1978.

[17] P. M. McDonald. Seed dissemination in small clear cuttings in North-central California (Vol. 150). US Department of Agriculture, Forest Service, Pacific Southwest Forest and Range Experiment Station, 1980

[18] P. S. Sreejith, R. J. Praseeja, R. J., V.V Asha. A review on the pharmacology and phytochemistry of traditional medicinal plant, Glycosmis pentaphylla (Retz.) Correa. Journal of Pharmacy Research, Vol. 55, No. 55, 2723-2728, 2012 .

[19] F. Ahmad, H.B.M Ismail, M. Rahmani. Arborine, a Larval Growth Inhibitor from Glycosmis pentaphylla. Pertanika Journal, Vol. 11, No. 1, 23-30, 1996

[20] M. H. Shoja, N. D. Reddy, P. G. Nayak, K. K. Srinivasan, C. M. Rao, C. M. Glycosmis pentaphylla (Retz.) DC arrests cell cycle and induces apoptosis via caspase- $3 / 7$ activation in breast cancer cells. Journal of ethnopharmacology, Vol. 168, $50-60,2015$.

[21] M. A. Howlader, F. Rizwan, S. Sultana, M. R. Rahman, K. M. Shams-Ud-Doha, R. Mowla, A. S Apu. Antimicrobial, antioxidant and cytotoxic effects of methanolic extracts of leaves and stems of Glycosmis pentaphylla (Retz.). Journal of Applied Pharmaceutical Science, Vol. 1, No. 8, 137, 2011

[22] A. De, S. Nath, A. K. Das, S. K. Bandyopadhyay, M. C. Banerjee, T. K. Mandal. Effects of Glycosmis pentaphylla leaf powder against chronic arsenicosis in rats. International Journal of Pharmaceutical Sciences and Research, Vol. 8, No. 5, 2287-2297, 2017.

[23] A. T. Hoque, R. Ahmed, M. Uddin, M. Hossain, M Allelopathic effect of different concentration of water extracts of Acacia auriculiformis leaf on some initial growth parameters of five common agricultural crops. Pakistan Journal of Agronomy, Vol. 2, No. 2, 92-100, 2003. 